\title{
LA ENAJENACION DEL TRABAJO EN CONTRIBUCIÓN A LA CRÍTICA DE LA ECONOMÍA POLÍTICA Y FORMACIONES ECONÓMICAS PRECAPITALISTAS
}

Saby Lazarte Oyague

Universidad Ricardo Palma

\begin{abstract}
RESUMEN
El pensar que Marx refleja en sus obras es indesligable de la filosofía y de la concepción del hombre, en cuanto es un ser social depende del trabajo para su supervivencia. De manera general tratamos: al sujeto que se desenvuelve y se realiza mediante el trabajo, en tanto que los sujetos como esencia humana abstracta forman parte de las diferentes sociedades que Marx relata, diferenciando las sociedades capitalistas de las no capitalistas; y de manera particular, nos referimos a la diferencia entre trabajo libre y trabajo asalariado, que depende de las diferentes etapas del desarrollo social donde el sujeto que se objetiva a través del trabajo termina enajenándose, perdiendo conciencia de su ser y asumiendo simples medios de subsistencia.
\end{abstract}

\section{PALABRAS CLAVE}

Trabajo / Enajenación / Sociedad / Capitalismo / Hombre.

\begin{abstract}
The thought of Marx reflected in his works, is inseparable from philosophy and the conception of man as a social being is dependent on labor for survival. Generally try: the subject which it operates and is done through work, while subjects as abstract human essence part of the different societies that Marx describes the capitalist differentiating non-capitalist societies; and particularly we refer to the difference between free and paid work depends on the different stages of social development where the subject is objectified by the alienating work ends losing consciousness of his being and livelihoods assuming simple.
\end{abstract}

KEYWORDS

Labor / Alienation / Society / Capitalism / Man. 
Hay que evitar ante todo el hacer de nuevo de la «sociedad» una abstracción frente al individuo. El individuo es el ser social (Marx, 1974, p. 146).

\section{EL TRABAJO COMO CATEGORÍA}

El sujeto en las diferentes sociedades es parte del desarrollo histórico que engendra las abstracciones del mundo moderno, las cuales analizadas y teorizadas bajo el método de la economía política nos sitúa frente a la categoría más simple, "el trabajo". Al respecto dice Marx:

El trabajo es una categoría del todo simple [...], sin embargo, concebido económicamente bajo esta simplicidad el trabajo es una categoría tan moderna como lo son las condiciones que engendran esta abstracción (Marx, 1969, p. 231).

Con el pensar moderno se entiende el trabajo como una forma de producción, como una actividad que vincula al capital y no se podría entender aislado. Marx nos refiere un entendimiento global, partimos así del trabajo como categoría simple sin desligarlo del proceso histórico en que se desenvuelve.

El trabajo en sí mismo ha existido en todas las sociedades como categoría simple, como parte del encuentro del hombre con la naturaleza. Es actividad humana primordial para la realización plena del ser del hombre. Engels se refiere a que el trabajo es la primera condición fundamental de toda la vida humana. El mono evoluciona, camina semierecto, hace uso de sus extremidades, en especial de su mano, que le sirve para arrancar y tomar el alimento, en el tránsito del mono al hombre. El uso de la mano ha tendido a ejecutar ciertas operaciones diferenciando al hombre de otros animales. Así el trabajo al igual que el lenguaje son los incentivos del desarrollo del hombre, dándose por evidenciado un progreso conforme a las necesidades propias de él. El trabajo comienza con la elaboración de herramientas que son empleadas en la caza y en la pesca, estableciéndose la realización del hombre en cuanto hombre, el trabajo como medio para dominar la naturaleza, transformándola de tal manera que genere su bienestar.

El trabajo es, dicen los economistas, la fuente de toda riqueza. Y lo es, en efecto, a la par con la naturaleza, que se encarga de su- 
ministrarle la materia destinada a ser convertida en riqueza por el trabajo. Pero es infinitamente más que eso. El trabajo es la primera condición fundamental de toda la vida humana, hasta tal punto que, en cierto sentido, deberíamos afirmar que el hombre mismo ha sido creado por obra del trabajo (Engels, 1961, p. 142).

En este sentido es que asumimos al trabajo como la primera actividad humana, con un desarrollo histórico que corresponde al entorno social, pero que a través de las épocas las concepciones del trabajo fueron distintas y en el mundo moderno -como dice Marx-se hacen "abstracciones" de categorías simples como si nada tuviese que ver una época con otra, pero afirmamos que cada época de desarrollo social contiene en sí, de manera abstracta, la concepción del trabajo de una sociedad anterior y así concatenadamente. En la sociedad moderna el trabajo es visto como parte última del proceso de producción, pero si relacionamos la producción con el trabajo, también debemos tener en cuenta el desarrollo histórico que genera rasgos comunes en todas las sociedades. Marx señaló: "Todas las épocas de la producción poseen ciertos rasgos distintivos en común, determinaciones comunes" (1969, p. 210). Estas determinaciones nos llevan a situar al hombre frente al trabajo como un ser que asume su colectividad, situándolo a la vez frente a otros seres con rasgos comunes sin individualidades ni fines particulares.

Si en las sociedades antiguas, el desarrollo del trabajo por la producción que realizaban los sujetos era de manera uniforme, en las sociedades modernas existe un giro que marca con rudeza la concepción del trabajo. En la concepción del hombre, conforme se hacía evidente su progreso, también se enraizaba un hombre cada vez más particular. Validamos la frase de Hobbes: "El hombre es un lobo del hombre", lo que hace imposible ver al trabajo sin mostrar la base antropológica que marca el ser del trabajo. Encontramos en base el concepto de "trabajo" que Marx presentó como una concepción del hombre como debe ser y como está siendo, de donde se desprende:

- El ser esencial del hombre (lo que debe ser), y

- El ser existente (lo que está siendo)

Entonces el hombre es real porque desarrolla el trabajo, porque hay algo que le permite ser real y esta es la naturaleza. El hombre es un ser natural, pero es hombre porque trabaja, en la actividad material de transformación de la naturaleza, se transforma también el hombre, por esta 
razón, lo que los individuos son depende de las condiciones materiales de su producción.

La lectura de la Introducción a la crítica de la economía política ${ }^{1}$, nos presenta cuatro partes principales que tienen como eje fundamental la producción en general y la producción en sus distintas formas de la economía política.

\section{LA PRODUCCIÓN EN GENERAL}

Marx compara, analiza y muestra las transformaciones de la sociedad a partir de la producción material, observa que la relación de los individuos con la sociedad era natural; el individuo se sentía parte de la naturaleza y se dejaba de lado el entorno histórico. La sociedad burguesa trae consigo diferentes formas de relaciones sociales en el cual las condiciones median a un individuo social con fines privados. Se presenta el sentido histórico del hombre, Marx lo sitúa en la sociedad; dice : "El hombre es un Zoon politikon" (Marx, 1969, p. 209) ; se subraya la imagen errada de los economistas modernos acerca del hombre, pues lo colocan como un individuo capaz de producir solo abstracciones, que resultan erróneas pues el hombre es parte de un todo unitario.

Hay una relación histórica cuyo origen se ignora. La producción es a cada momento de individuos sociales hallando Marx rasgos comunes en todas las épocas, "las determinaciones que valen para la producción en general deben precisamente ser separadas" (1969, p. 210). Los modernos economistas confundían la diferencia esencial de estas determinaciones, como son : sujeto-humanidad-objeto-naturaleza, lo que Marx propone es la reestructuración económica de la producción en general distinguiendo: Producción en general-Ramas de producción particular-Totalidad de la producción, así las condiciones generales de producción debe exponer primero "las condiciones sin las cuales no es posible la producción" (1969, p. 211); y segundo "las condiciones que prestan más o menos vuelos a la producción” (p. 212).

En ambos casos, la disposición de razas, climas y condiciones naturales (situación marítima, fertilidad del suelo), son más favorables que

1 En nuestro texto lo encontramos como apéndice bajo el título: Preliminar a una crítica de la economía política. 
otras para la producción; llegando a resaltar las características comunes de la producción con la distribución sin confundir las diferencias históricas con leyes humanas generales. Pero en todo sentido la producción presupone la apropiación de algo, entonces toda propiedad es apropiación de la naturaleza por el individuo en una determinada forma de sociedad.

\section{LA RELACIÓN GENERAL DE LA PRODUCCIÓN CON LA DIS- TRIBUCIÓN, EL CAMBIO Y EL CONSUMO}

Esta relación se establece a partir de los economistas que consideran, "la producción demasiado exclusivamente como un fin propio" (1969, p. 216), de donde se desprenden las siguientes categorías: Producción (los miembros de la sociedad se apropian de los productos de la naturaleza para las necesidades humanas). Distribución (determina la participación del individuo en la producción). Cambio (trae productos particulares generados por la producción). Consumo (los productos se convierten en objetos de disfrute).

Este tratamiento de conceptos genera un tratado que no parte de la realidad, Marx analiza las relaciones reales y encuentra: Producción y Consumo: La producción es también inmediatamente consumo, porque para la producción se consume en la naturaleza y el producto recibe su acabado final en el consumo, entonces "la producción produce, pues, únicamente el objeto del consumo, o sea que produce objetiva y subjetivamente" (1969, p. 218).

Producción y Distribución: Se establecen las categorías de doble manera, primero como agente de producción; y segundo como origen de rentas que es la forma determinada de la distribución. Podemos considerar que el Capital como agente de producción, supone el interés y la utilidad como formas de distribución. El trabajo como agente de producción y el salario como forma de distribución.

Cambio y Circulación: La circulación es el cambio considerado en su totalidad. El cambio es el mediador entre la producción, distribución, y consumo. El cambio se da en tres momentos: primero, como cambio de actividades y capacidades que se efectúa en la producción misma. Segundo, como cambio de los productos, en la medida en que es el instrumento que sirve para proveer el producto acabado destinado al consumo. Y tercero, como cambio entre productores cambistas, determinado por la producción 
de la actividad productora. Marx refiere: "El resultado a que llegamos no es que la producción, la distribución, el cambio, el consumo, son idénticos, sino que todos ellos son miembros de una totalidad, diferencias en una unidad" (1969, p. 226).

\section{EL MÉTODO DE LA ECONOMÍA POLÍTICA}

Se muestra un procedimiento de lo que consideró "Método Científico", el método que propuso Marx, buscó comenzar por lo real y lo concreto para elevarse luego a la comprensión de las relaciones de los elementos simples, se tiene presente el análisis como punto de partida para la abstracción teórica de la fundamentación real que para Marx es lo concreto pensado, dice: "Lo concreto es concreto, porque es la síntesis de muchas determinaciones, es decir unidad de lo diverso" (1969, p. 228). Es por la vía del pensamiento que las determinaciones abstractas conducen a la reproducción de lo concreto. En este sentido, no deja de lado la fundamentación teórica de un individuo en el propio pensar, dice: "El sí mismo abstraído y fijado para sí es el hombre como egoísta abstracto, el egoísmo en su pura abstracción elevado hasta el pensamiento" (1974, p. 191).

Producto del método son las categorías simples que siguen las leyes del pensar abstracto, que se vincula al proceso histórico real. Marx pone de ejemplo el dinero que ha existido antes que el capital, el que ha expresado "relaciones dominantes de un todo poco desarrollado aun" (1969, p. 230), y sin la existencia del dinero hay sociedades desarrolladas con formas elevadas de la economía, tales como la cooperación; en las cuales el dinero no es prioritario, entre estas sociedades menciona al Perú.

Además, muestra que el trabajo, de acuerdo a las determinaciones abstractas resulta el producto de condiciones históricas sólo válidas dentro de un mismo marco de referencia. Así, la economía burguesa es representación concreta de la organización histórica de la sociedad, la producción aparece así como un factor predominante de consecuencia histórica. Marx analiza a la sociedad burguesa vinculada a las formas de producción, el capital como potencia económica que lo abarca todo. "Debe constituir el punto inicial y el punto final y ser desarrollado antes que la propiedad rustica" (1969, p. 236). Aquí relata Marx el papel preponderante del capital a través del desarrollo histórico de las sociedades con determinaciones abstractas donde se mantiene la unidad. Estas abstracciones no son otra cosa que abstracciones de determinaciones concretas, porque "la abstracción que se conoce como abstracción se conoce como nada; tiene que abandonarse a 
sí misma, a la abstracción, y llega así junto a un ser que es justamente su contrario, junto a la naturaleza"(1974, p. 205).

\section{RELACIÓN: PRODUCCIÓN-MEDIOS DE PRODUCCIÓN}

En esta sección Marx se refiere a dos partes bien definidas. La primera trata de ocho puntos, los cuales mencionamos:

- La guerra es desarrollada antes que la paz.

- Relación del método idealista y realista.

- Hechos secundarios y terciarios.

- Sobre el materialismo de esta concepción.

- Dialéctica de los conceptos, fuerza productora y relaciones de producción.

- La relación desigual entre el desarrollo de la producción material y la producción antigua.

- Concepción necesaria. Justificación del azar.

- Las determinaciones naturales subjetivas y objetivas.

La segunda parte trata de la relación entre la sociedad moderna y el arte griego. Marx realiza una comparación que versa sobre el sentido de la mitología griega, el cual se aclara señalando su modo de producción y de consumo de acuerdo a sus necesidades. La sociedad moderna posee sus imágenes y representaciones (referidas a su superestructura), la cual pierde sentido llevándola al mundo griego sus representaciones artísticas, lo que conlleva también su modo de producción. Las sociedades así vistas muestran aspectos diversos que, desde el esquema de la producción, es condicionante de sus actividades jurídicas, artísticas, etc.

Cuando se oculta la relación trabajo-producción, el hombre que trabaja para su beneficio o el de su comunidad transforma la naturaleza, y el fruto del trabajo en el hombre establece las relaciones de producción reafirmando su esencia por el trabajo mismo: "La economía política oculta la enajenación esencial del trabajo porque no considera la relación inmediata entre el trabajador (el trabajo) y la producción" (1974, p. 108); pero, bajo una sociedad moderna, el hombre cuanto más producción tiene, más fuera de sí se encuentra. El trabajador que debería ser el dueño de su producto termina desapropiándose, el producto pasa a ser de otro (para otro). Así, el hombre trabajador va perdiendo su identidad ya que se desapropia de 
su producción, se enajena, deja de ser "ser esencial", dependiendo de las condiciones externas que lo hacen someterse y vivir en un estado de conciencia, enajenado de su realidad del mundo y de su producto.

\section{TRABAJO LIBRE Y TRABAJO ASALARIADO}

Partimos del hecho que el trabajo es la actividad fundamental del hombre, la condición natural de producción para el individuo, el hombre se identifica con la naturaleza y la asume como propiedad, es parte de él y de su comunidad. La realización del trabajo no es mediada por ningún factor que conlleve a la separación del trabajador y su propiedad; el hombre satisface sus necesidades. Marx refiere:

... las condiciones originarias de la producción aparecen como presupuestos naturales, como condiciones naturales de existencia del productor, exactamente igual que su cuerpo viviente, el cual por más que él lo reproduzca y desarrolle, originariamente no es puesto por él mismo sino que aparece como el presupuesto de sí mismo; su propia existencia (corporal) es un supuesto natural, que él no ha puesto (1971, p. 450).

En la producción antigua no se observa que aparezca la riqueza como objetivo de la producción. Si bien existía el dinero antes que el capital, asumimos que en esta etapa de desarrollo social el hombre se hallaba como puesto para un bien común, sin pensarlo asumían en la producción antigua una valoración moral, donde el hombre es el objetivo de la producción y por tanto del trabajo. Pues el trabajo se daba en forma libre, sin mediación, sin intercambio de dinero ni acumulación de riqueza.

La riqueza sólo aparece como fin en sí mismo entre los pocos pueblos comerciantes- monopolistas del comercio itinerante- que viven en los poros del mundo antiguo, tal como los judíos en la sociedad medieval. La riqueza es aquí por un lado, cosa, algo realizado en cosas, en productos materiales, a los cuales se contrapone el hombre como sujeto por otra parte como valor, es mero control sobre trabajo ajeno, pero no con el objetivo del dominio sino del goce privado (1971, p. 447).

En la sociedad moderna, bajo las concepciones de la economía política, cambia este trabajo libre y pasa a ser la riqueza objetivo de la producción, en consecuencia, la producción como objetivo del hombre. Las con- 
cepciones del mundo moderno generan la relación capital-trabajo, Marx se pronuncia frente a la explotación de los trabajadores por parte del capitalista: esta explotación por la cual el trabajador es menospreciado en sus derechos y obligado a vivir materialmente en condiciones infrahumanas. Con una perspectiva económica en el sistema capitalista, el trabajador es quien no posee nada. Recibe un salario por el trabajo puesto en el producto, quedando el producto en poder del empresario, quien lo vende e incluye una plusvalía o utilidad del capitalista, mientras el trabajador queda confinado en la clase proletaria, absolutamente sin derechos y sin energías para exigirlos. El capitalista se va enriqueciendo a velocidades cada vez mayores.

De este modo, la enajenación del trabajo termina convirtiendo al ser esencial del hombre, en un ser ajeno a él mismo. Para Marx: "El obrero sufre más que nunca en su estado de declinación social" (174, p. 59). En este sentido, hay una liberación implícita -que busca el hombre en estado enajenado- por la cual solo sería eficaz en cuanto sea consciente del estado enajenado en que se encuentra, y que busca hacerle frente tomando conciencia de su ser esencial en sí mismo. Además de tener en claro que ser obrero es existir como ser enajenado, entonces solo concientizando al obrero es que el hombre se conduce a la emancipación. Esto es, a la liberación de esta forma de opresión, pero queda claro también que la concientización del obrero se da en la concientización del ser obrero (ser subordinado, dependiente), y liberar al hombre, o al ser que se encuentra en todo hombre, con la facultad de ser y pensar, transformando el mundo para su beneficio colectivo.

El trabajo asalariado se caracteriza por el pago que recibe el trabajador (obrero) por su labor, teniendo importancia enorme la riqueza. El capitalista adquiere con dinero el trabajo de los obreros; estos venden su fuerza de trabajo que se transforma en mercancía y el trabajo pierde su ser en sí. El paso de trabajo libre a trabajo asalariado, se debe en gran medida al valor que obtiene el dinero en la sociedad moderna: el dinero hace que se vea la fuerza de trabajo del obrero como mercancía:

Los obreros cambian su mercancía, la fuerza de trabajo, por la mercancía del capitalista, por el dinero, y este cambio se realiza guardándose una determinada proporción, tanto dinero por tantas horas de uso de la fuerza de trabajo. ... Por consiguiente el salario no es más que un nombre especial con que se designa el precio de la fuerza de trabajo, o lo que suele llamarse precio del trabajo, el nombre especial de esa peculiar mercancía que sólo toma cuerpo en la carne y la sangre del hombre $(1985$, p. 86). 
El hombre deja de lado su ser esencial y enajena el trabajo, lo que estaba destinado para bien del hombre obtiene un final aniquilante. Así, la enajenación se da explícitamente en la sociedad moderna y se incrementándose la sumisión, en el hecho que al aumentar la racionalización y mecanización del proceso de trabajo, la actividad del trabajador pierde su carácter de actividad. Pero no sólo la enajenación del trabajo en la sociedad moderna, sino también de una manera implícita en la sociedad de esclavos. o en la época medieval, donde la mercancía se encuentra bajo una abstracción que se da en la realidad: Por tanto, la enajenación del trabajo no es sólo un producto histórico de una sociedad capitalista moderna, sino también de otras sociedades. La enajenación del trabajo está de una manera oculta en la sociedad donde los esclavos son parte de la estructura, sólo que no se muestra la liberación del hombre como hombre en sí, ya que en las sociedades medievales o de esclavos, se tenía como parte de la estructura social tener como posesión esclavos (hombres que pertenecen a otros hombres). Estos eran vendidos a los dueños en forma de mercancías, dando riqueza y acumulación de dinero a los amos o dueños; dice Marx:

El esclavo no está en ninguna relación con las condiciones objetivas de su trabajo, sino que el trabajo mismo, tanto en la forma de esclavo como en la del siervo es colocado como condición inorgánica de la producción dentro de la serie de los otros seres naturales, junto al ganado o como accesorio de la tierra (1971, p. 449).

Pues el esclavo no vende su fuerza de trabajo al esclavista, mas bien el esclavo es vendido como mercancía y que puede pasar de dueño a otro, sin pertenecerle nada en calidad de esclavo. Pero como esclavo realiza un trabajo, y bajo el concepto de trabajo esta situación del hombre es una situación implícita de enajenación del trabajo, ya que aquí también el hombre como ser en sí no es dueño de nada; se pierde porque le pertenece a otro. Mientras que el obrero puede dejar al capitalista y así eliminar la enajenación del trabajo; el esclavo, no.

De aquí que en la sociedad moderna se asuma que el hombre es un ser en sí mismo esencial depende de las condiciones en las que se sitúe, las cuales no pueden desprenderse de la categoría del trabajo como enajenación.

De la relación del trabajo enajenado con la propiedad privada se sigue, además, que la emancipación de la sociedad de la propiedad privada, etc., de la servidumbre, se expresa en la forma política 
de la emancipación de los trabajadores, no como si se tratase de la emancipación de éstos, sino porque su emancipación entraña la emancipación humana general; y esto es así porque toda la servidumbre humana está encerrada en la relación del trabajador con la producción (1985, p. 117).

Así, Marx conduce a los hombres a la acción, a una transformación de la naturaleza, sin dejar de lado el ser auténtico del hombre. Ya que con la economía política señaló que se ocultan las verdaderas formas de ser del hombre en relación con su ser histórico social, que se origina de una estructura formada según el progreso que el propio hombre crea. Marx con sus críticas a la economía política sitúa la base real del hombre como debe ser, relatando al hombre como es y cómo se desenvuelve en la principal actividad, el trabajo.

En tanto que la división del trabajo eleva la fuerza productiva del trabajo, la riqueza y el refinamiento de la sociedad, empobrece el obrero hasta reducirlo a máquina [...]. Lo que como hombre no puedo, lo que no pueden mis fuerzas individuales, lo puedo mediante el dinero.

\section{PRODUCCIÓN CAPITALISTA Y NO-CAPITALISTA}

En Formaciones económicas precapitalistas ${ }^{2}$, Marx analiza las relaciones por las cuales se establece el nexo entre el trabajo asalariado y el capital, mostrando también el quiebre entre el trabajo libre con el trabajador individual. Se asume la propiedad como una entidad comunitaria dando como resultado un producto histórico, podemos establecer dos supuestos: primero, la dependencia entre trabajo asalariado y capital se da por el trabajo libre, que genera un cambio por dinero. Segundo, hay una separación entre el trabajo libre con el medio de trabajo, y el material de trabajo. Así, primero presupone la existencia de individuos libres, los cuales intercambian su trabajo por un salario (dinero); segundo, presupone la separación del trabajador con los medios de producción, los cuales le pertenecen a otro.

Marx describe tres formas de propiedad, a la vez que las examina constituyendo la base para entender el modo de producción capitalista.

2 En nuestro texto, "Formas que preceden a la producción capitalista". Cf. MARX, Karl. Elementos fundamentales para una crítica de la economía politica (borrador) 1857-1858. Buenos Aires: Siglo XXI Editores. 1971. Vol.1. 
Desde el análisis de las sociedades no capitalistas, estableciendo las diferencias entre el régimen de producción capitalista y no capitalista.

Primero, menciona a tribus o sociedades asiáticas donde se presentaba un tipo de organización de manera natural y, a la vez, en comunidad, donde todavía existía cierto misticismo respecto a la tierra y formas de producción. Estableciéndose como condición objetiva de la producción del hombre la propiedad, dice: "la entidad comunitaria natural no aparece como resultado sino como supuesto de la apropiación colectiva (temporaria) del suelo y de su utilización" (1971, p. 434). Si se desarrolla un orden más despótico o democrático se debe al dominio y representación de un jefe donde se realiza el trabajo colectivo, lo que puede estar formalizado como en México, Perú, antiguos celtas y algunas tribus de la india.

Segundo, el individuo se comporta como propietario a través del proceso del trabajo por la apropiación de la tierra, encontrándose como miembro del Estado. Por este medio la entidad comunitaria ya no es la tierra sino la cuidad, señaló: "En este caso, sigue siendo presupuesto para la apropiación del suelo el ser miembro de la comunidad, el individuo es propietario privado" (1971, p. 437). Aquí la propiedad está entendida de dos formas, en un primer momento la propiedad es del individuo porque es el productor; y a la vez no es del individuo porque le pertenece al Estado; pero en cuanto que la propiedad es parte del Estado, y del individuo también, es entonces como sigue siendo propietario pero mediado.

Tercero, el propietario es solo miembro individual en cuanto es poseedor de una parte específica de la tierra, sea esta hereditaria o no. "Las tribus de los estados antiguos estaban constituidas de dos maneras: sobre la base de linajes o sobre la base de lugares. Las tribus en base de linajes superan en antigüedad a las tribus basadas en el lugar y en casi todas partes fueron suplantadas por éstas" (1971, p. 441).

Luego de hablarnos de la historia antigua y de la forma asiática, Marx trata sobre la propiedad entre los germanos. "Entre los germanos, entre quienes los cabezas de familia se establecen en los bosques, separados por grandes distancias, la comunidad solamente existe, considera solo externamente, en virtud de cada acto de reunión de sus miembros, aun cuando su unidad existe en sí" (1971, p. 442). No hay unión sino una reunión de diversos sujetos autónomos que son propietarios de la tierra como unidad. Queda definida entonces la característica peculiar de esta 
forma, la propiedad individual no aparece como una propiedad de una familia autónoma. Finalmente Marx, estableció dos diferencias marcadas entre las formas de producción antigua y la producción burguesa.

\begin{tabular}{|c|c|}
\hline PRODUCCIÓN ANTIGUA & PRODUCCIÓN BURGUESA \\
$\begin{array}{c}\text { 1. La riqueza no aparece como obje- } \\
\text { tivo de la producción. }\end{array}$ & $\begin{array}{c}\text { 1. La riqueza aparece es como obje- } \\
\text { tivo de la producción }\end{array}$ \\
$\begin{array}{c}\text { 2. El hombre es el objetivo de la } \\
\text { producción (valoración moral) }\end{array}$ & $\begin{array}{c}\text { 2. La producción como objetivo del } \\
\text { hombre }\end{array}$ \\
\hline
\end{tabular}

Se entiende la producción antigua como una "relación preburguesa del individuo (1971, p. 448). "Lo que el Señor Proudhon llama la génesis extraeconómica de la propiedad" (p. 448). También estable un proceso histórico en la formación capitalista donde se dan por separado, las condiciones objetivas del trabajo y del trabajador; del capitalista y el trabajador desprovisto de propiedad.

\section{A MODO DE CONCLUSIÓN}

La propiedad, significará el actuar del hombre frente a la naturaleza para su subsistencia, de aquí se desprenden dos relaciones básicas. Por un lado, el comportamiento que el individuo poseerá respecto a una entidad comunitaria, que pudo tener como antecedente una forma de organización originaria, ya sea esta una tribu, o no, es decir, el comportamiento del individuo frente a los otros que se encuentra en condiciones análogas a él. Por otro lado, el comportamiento del individuo con el suelo como algo suyo, mediado por esta entidad comunitaria. Propiedad significa entonces "permanecer a una tribu (entidad comunitaria), (tener en ella existencia subjetiva-objetiva) y por intermedio del comportamiento del individuo con la tierra, con la condición originaria de la producción".

Por último, lo que ocupa la atención de Marx es un proceso histórico de "el comportamiento del trabajo con el capital" (p. 458). Es así que en la sociedad burguesa capitalista el dinero es la base fundamental para la riqueza, es el dinero en forma de capital que presupone más dinero. "La producción basada sobre el valor de cambio y la entidad comunitaria basada sobre el intercambio de estos valores de cambio supone y produce la separación del trabajo con respecto a sus condiciones objetivas" ( $p$. 
472). Marx observó cómo el capital presupone inversión, cambio y trabajo; este pequeño capital que surge se hace necesario en la producción de las fábricas de vidrio, de papel, etc., de donde esta producción presupone el consumo, por el cual se da el valor de cambio.

\section{REFERENCIAS BIBLIOGRÁFICAS}

ENGELS, Federico

1961 Dialéctica de la Naturaleza. Trad. del alemán, Wenceslao Roces. México: Grijalbo.

MARX, Karl

1969 Crítica de la economía política. Versión española de Javier Merino. México: Editora Nacional.

1971 Elementos fundamentales para una crítica de la economía política. (Borrador) 1857-1858. Vol. 1. Buenos aires: Siglo XXI Editores.

1974 Manuscritos de economía y filosofía. Madrid: Alianza Editorial.

1985 El manifiesto comunista. Madrid: Sarpe. En otros escritos: Trabajo asalariado y capital. 